\title{
ADMINISTRAÇÃO PÚBLICA PLURICÊNTRICA
}

\author{
AleXandRe Santos DE ARAgão*
}

I - O esgotamento do modelo centralizado e hierárquico de administração pública. II - Autonomia. III - O princípio da descentralização administrativa. IV - Conceito material de descentralização administrativa. $V-$ Controles sobre os órgãos e entidades descentralizados. VI - $O$ caso das agências reguladoras. VII - Conclusões.

L'État n'est plus l'incarnation d'une idée: il est un appareil, un ensamble de mécanismes techniques.

Georges Burdeau

Traité de Science Politique, t. X

I - O esgotamento do modelo centralizado e hierárquico de administração pública

Sob o prisma da organização do aparato administrativo, o pluralismo da sociedade e do Estado faz com que este tenha definitivamente mitigado o caráter unitário que possuía nos oitocentos, ${ }^{1}$ que já começara a ruir com o advento dos entes locais

* Procurador do Estado do Rio de Janeiro. Advogado. Mestre em Direito Público pela U.E.R.J. Professor contratado de Direito Administrativo da Universidade do Estado do Rio de Janeiro U.E.R.J. Professor da Pós-graduação em Direito Econômico Intemacional da PUC/RJ. Membro das Comissões de Direito Administrativo e de Direito Constitucional do Instituto dos Advogados Brasileiros - IAB.

1 Eduardo García de ENTERRf́A descreveu o modelo administrativo napoleônico da seguinte maneira: “as funções ativas se reservam apenas aos orgãos com agentes individuais ou monocráticos, os quais se relacionam entre si mediante a técnica do escalonamento hierárquico, enquanto que os orgāos colegiais ficam reduzidos a funçōes consultivas ou deliberativas situadas lateralmente à linha hierárquica, assistindo-a e complementando-a, mas sem diminuir a sua substantividade e prevalência" (Revolución Francesa y Administración Contemporánea, Civitas, 4* ed., 1998, p. 125). 
autônomos e das entidades da administração indireta, sujeitos, no entanto, a uma tutela quase absoluta da Administração central.

Com o avanço da pluralidade e complexidade, inclusive tecnológica, da sociedade, este processo fragmentário da administração pública chegou a um ponto ótimo com o surgimento dos órgãos e entidades independentes, ou seja, dotados de uma verdadeira/reforçada autonomia, de uma descentralização material, mais capazes de ponderar os diversos interesses sociais presentes. ${ }^{2}$

Esta evolução, mais do que simplesmente consistir em uma mudança dos paradigmas do Direito Administrativo, é reflexo da complexização da sociedade. Os diversos interesses que no Estado pluriclasse recebem a proteção legislativa, a tecnização dos meios necessários à sua satisfação e a exigência de tais interesses serem tratados com imparcialidade frente ao jogo político-partidário ${ }^{3}$ fizeram com que o Estado fosse progressivamente criando em seu interior novos centros de poder dotados de diferentes modelos organizativos.

O tema, desta forma colocado, não é apenas matéria de estudo de juristas, mas também de filósofos e cientistas políticos.

Gilles DELEUZE e Félix GUATARRI observam que "a oposição clássica entre o segmentário e o centralizado afigura-se pouco pertinente. Não só o Estado se exerce sobre segmentos que ele mantém ou deixa subsistir, mas possui a sua própria segmentaridade e a impõe. (...) O sistema político moderno é um todo global, unificado e unificante, mas porque implica um conjunto de subsistemas justapostos, imbricados, ordenados, de modo que a análise das decisões revela toda espécie de compartimentações e de processos parciais que se prolongam uns nos outros sem defasagens ou deslocamentos. A tecnocracia procede por divisão do trabalho segmentário (inclusive na divisão internacional do trabalho). A burocracia só existe através das suas repartições e só funciona através de seus 'deslocamentos de meta' e 'desfuncionamentos' correspondentes. A hierarquia não é somente piramidal: o escritório do chefe está tanto no fundo do corredor quanto no alto da torre. Em suma, tem-se a impressão de que a vida moderna não destruiu a segmentaridade, mas que ao contrário, a endureceu singularmente." ${ }^{4}$

2 CHEVALLIER, Jacques, Vers un Droit Postmoderne, constante da obra coletiva dirigida por Jean CLAM e GILLES Martin Les Transformations de la Régulation Juridique, LGDJ, Paris, 1998, p. 35. Costantino MORTATI observa que "o escopo da descentralização não é apenas o de aproximar a Administração dos cidadãos para que a atuação administrativa se dê, de um lado, de forma mais rápida e cômoda para estes, e de outro, mais consentânea com as suas necessidades, em virtude do maior conhecimento destas propiciado pela descentralização, mas também o de fracionar o poder do Estado evitando a sua concentração nas mesmas mãos" (Istituzioni di Diritto Pubblico, Tomo I, CEDAM, Padova, 10 ed., 1991, p. 634).

3 O Conselho de Estado da Itália já decidiu que o "fracionamento institucional entre órgãos distintos do complexo das atividades unitariamente destinadas à satisfação de interesses públicos... é uma das mais concretas e indiscutíveis garantias da atuação imparcial" (apud CASSESE, Sabino, Le Basi del Diritto Amministrativo, Ed. Garzanti, Milão, $6^{a}$ ed., 2000, pp. 168/9).

4 DELEUZE, Gilles e GUATARRI, Félix, Micropolítica e Segmentaridade, in Mil Platôs, vol. 3, Editora 34, Rio de Janeiro, 1996, coordenação da tradução de Ana Lúcia de OLIVEIRA, pp. 
Em aguda análise Dieter FREIBURGHAUS afirma que as mudanças do Estado podem ser explicadas em razão " da sociedade ter se tornado cada vez mais complexa. Esta complexidade é simultaneamente aumentada e controlada pelo desenvolvimento de um número crescente de subsistemas cada vez mais especializados, tais como o Estado, a economia, a ciência, os transportes, as mídias etc. Esta especialização, como toda divisão de trabalho, aumenta a capacidade produtiva, lato sensu, da sociedade. Mas há uma contradição: Os subsistemas, de uma parte, se tornam mais fortes através do aumento da sua autonomia, da sua capacidade de autogestão; de outra parte, dependem cada vez mais uns dos outros e para poderem coordenar as suas atividades. Esta coordenação se faz pela comunicação, pela troca de informações. Tal comunicação intersistêmica é tão complicada e difícil que não há como ser assegurada mediante uma planificação tradicional, mas apenas através de processos interativos e de processos de aprendizagem. O Estado, enquanto primus inter pares dos subsistemas da sociedade moderna, é intensamente implicado nesta coordenação. Ele é o responsável em última instância pela integração da sociedade, o que significa que hoje ele é, sobretudo, o responsável pelo bom funcionamento desta engrenagem". 5

Devemos ter em vista que foi ultrapassada a separação absoluta que outrora se fazia entre Estado e sociedade. Há, outrossim, uma interpenetração entre ambos. $O$ Estado é um instrumento de organização da sociedade, cujo bem-estar é o seu objetivo. Sendo assim, a tecnicização, diferenciação e autonomização dos vários subsistemas sociais fez com que as esferas decisórias estatais passassem a se revestir das mesmas características. Ou seja, sem se tecnicizar, diferenciar e autonomizar internamente o Estado se distanciaria da sociedade a que incumbe regular. Uma regulação estatal homogênea, centralizada e desprovida dos meios técnicos necessários seria insuscetível de produzir os efeitos desejados em uma sociedade caracterizada pela heterogeneidade, pluralismo e complexidade técnica. ${ }^{6}$

85-6. Estes autores, talvez os mais importantes filósofos contemporâneos, afirmam mais adiante: "Não basta definir a burocracia por uma segmentaridade dura, com divisão entre as repartições contíguas, chefe de repartição em cada segmento, e a centralização correspondente no fundo do corredor ou no alto da torre. Pois há ao mesmo tempo toda uma segmentação burocrática, uma flexibilidade e uma comunicação entre repartiçōes, uma perversão de burocracia, uma inventividade ou criatividade permanentes que se exercem inclusive contra os regulamentos administrativos. Se KAFKA é o maior teórico da burocracia, é porque ele mostra como, num certo nível (mas qual? E que não é localizável), as barreiras entre repartições deixam de ser 'limites precisos', mergulham num meio molecular que as dissolve, ao mesmo tempo em que ele faz proliferar o chefe em microfiguras difíceis de reconhecer, de identificar, e que são tão pouco discerníveis quanto centralizáveis: um outro regime que coexiste com a separação e a totalização dos segmentos duros" (DELEUZE, Gilles e GUATARRI, Félix, Micropolítica e Segmentaridade, in Mil Platôs, vol. 3, Editora 34, Rio de Janeiro, 1996, coordenação da tradução de Ana Lúcia de OLIVEIRA, p. 91).

5 FREIBURGHAUS, Dieter, Le Developpement des Moyens de l'Action Étatique, constante da obra coletiva dirigida por Charles-Albert Morand, L'État Propulsif, Ed. Publisud, Paris, 1991, pp. 59 e 60.

6 Esta evolução do Estado decorre da crise que sobre ele se abateu no início do século, crise esta oriunda de dois fenômenos que se potencializaram mutuamente: a progressiva organização da 
A superação da oposição público/privado se conjuga com a "despolitização" de uma série de funções estatais, levando ao que Jacques CHEVALLIER denomina de "ruptura do monolitismo de uma Administração que evolui para a adoção de um modelo 'policêntrico', caracterizado pela coexistência de vários centros de decisão e de responsabilidade". ${ }^{7}$

José Eduardo FARIA ${ }^{8}$ observa que o Estado tende a perder a centralidade, a unidade e exclusividade diante da extrema diversidade de interesses privados e do crescente número de decisões econômicas tomadas fora do alcance da sua jurisdição.

De fato, quando surgiu a soberania moderna, concentrada nas mãos do Rei, foram extintas as muitas autonomias existentes na Idade Média. ${ }^{9}$ Em seguida, com o Estado liberal, procurou-se limitar o caráter absoluto do poder soberano através da atribuição de parcelas suas a órgãos do Estado (os três Poderes) e/ou a entes territoriais regionais ou locais. ${ }^{10}$ Nos últimos tempos, do ponto de vista interno, que é o que mais nos interessa, a soberania vem, inclusive através de dispositivos constitucionais, cedendo espaço a entes e órgãos públicos, colocados à parte do aparelho estatal central e hierarquizado, e a entidades e organismos sociais que sequer integram a estrutura do Estado.

sociedade com base em interesses específicos, o que desde então faz com que cada vez mais perca o seu caráter atomístico, e a deficiência dos meios jurídicos e institucionais que a própria sociedade possuía para fazer com que o Estado espelhasse a estrutura social crescentemente complexa e diferenciada (cf. CASSESE, Sabino, Lo "Stato Pluriclasse" in Massimo Severo Giannini, constante da obra coletiva L'Unità del Diritto - Massimo Severo Giannini e la Teoria Giuridica, Società Editrice Il Mulino, Bologna, 1994, p. 34). É justamente na adaptação destes meios jurídicos e institucionais às características da sociedade contemporânea, a fim de que a referida "crise do Estado" seja vencida, que consiste o objetivo do presente estudo.

7 CHEVALLIER, Jacques, Les Autorités Administratives Indépendantes, in Encyclopaedia Universalis, Paris, 1989, p. 177.

8 Globalização, autonomia decisória e política, constante da obra coletiva "1988-1998: Uma Década de Constituição", organizada por Margarida Maria Lacombe CAMARGO, Ed. Renovar, 1999, pp. 307-311.

9 Norberto BOBBIO (Teoría General del Derecho, Editorial Debate, Madrid, trad., Eduardo Rozo Acuña, 1999, p. 21), recorda que a "a formação do Estado moderno corre paralela à formação de um poder coativo cada vez mais centralizado e, portanto, à supressão gradual dos centros de poder inferiores e superiores ao Estado (...)".

10 Diversas teorias foram elaboradas para explicar estes fenômenos, sendo a principal delas a que sustenta que a soberania não foi dividida, tendo apenas ocorrido a partição do exercício dos poderes a ela inerentes. Menosprezando em certa medida estas elaborações teóricas, construídas para dar explicação a necessidades fáticas e políticas que, de qualquer forma, se imporiam, João Barbalho afirma que "os ciosos da inalienabilidade $\mathrm{e}$ indivisibilidade da soberania acharão esse plano attentatorio aos princípios... Mas isto não o torna máo; nem as constituições se fazem por amor à sciencia e unicamente em vista de especulações philosophicas; fazem-se em proveito e benefício dos povos. E a melhor para cada povo não será a que se basear em meros systemas theoricos (...) E si d'este feitio não se tiver por conciliada a theoria com o facto, a theoria com a realidade, força é então convir que vale o sacrifício de principios politicos abstratos (...). Na vida real dos Estados se apresentam muitas vezes phenomenos que desafiam os systemas estabelecidos pela sciencia" (in Ediçāo fac-similar dos "Comentários à Constituição Federal de 1891", Secretaria de Documentação e Informação do Senado Federal, 1992, p. 10). 
Note-se, a esse respeito, que a doutrina vem denominando o atual estágio da organização político-administrativa como o da "devolução de poderes", " caracterizado pela retomada de espaços de atuação pública por instituições parciais do Estado e da sociedade.

Nas palavras do filósofo político norte-americano Michael HERDT, "trata-se, efetivamente, de um elemento de mudança geral na maneira pela qual o poder marca o espaço, na passagem da modernidade à pós-modernidade. A soberania moderna sempre foi concebida em termos de território - real ou imaginário - e da relação desse território com o seu fora. É assim que os primeiros teóricos modernos da sociedade, de HOBBES a ROUSSEAU, compreendiam a ordem civil como um espaço limitado e interior que se opõe à ordem exterior da natureza, ou que dela se distingue. (...) A dialética moderna do fora e do dentro foi substituída por um jogo de graus e intensidades, de hibridismo, e artificialidade". ${ }^{12}$

Vital MOREIRA, citando BREUER, considera o surgimento de órgãos e entidades públicas autônomas em relação ao Poder estatal central como a "resposta necessária do moderno Estado social ao alargamento das suas tarefas. A autonomização de organismos administrativos é, portanto uma consequiência, em termos de diferenciação e especialização, da ampliação e diversificação das tarefas administrativas." Caracterizando a administração pública do Estado pluriclasse como "policêntrica" afirma, desta vez valendo-se de BROHM, que "quanto mais a colectividade se especializa e diferencia técnico-profissionalmente e se pluraliza ético-culturalmente, tanto menor se torna aquilo que é comum a todos e tanto maior necessidade existe de diferenciação político-administrativa para corresponder à diversidade dos apelos feitos aos poderes públicos". ${ }^{13}$

Estas reflexões não fugiram aos cultores do Direito Administrativo, e nem poderia ser o contrário, uma vez que a Administração Pública é o locus por excelência de concretização destes fenômenos juspolíticos. ${ }^{14}$

Primeiramente, os próprios Ministérios foram se multiplicando e se especializando de acordo com os cada vez mais numerosos e muitas vezes contraditórios (p. ex., desenvolvimento industrial versus meio ambiente) interesses cometidos ao

11 CHAPMAN, Brian, Devolução de Poderes a Instituições Autônomas, inclusive Entidades Profissionais e Universidades, IBCA, FGV, 1960, trad. Walter Wahrlich.

12 A Sociedade Mundial de Controle, constante da obra coletiva Gilles DELEUZE: uma vida filosófica, trad. Maria Cristina Franco FERRAZ, Ed. 34, 2000, pp. 358/9.

13 Administração Autónoma e Associações Públicas, Coimbra Editora, 1997, pp. 30, 31 e 35.

14 Este é, inclusive, um dos motivos da retomada dos estudos da organização administrativa, deixada em segundo plano durante muitos anos pelo equivocado entendimento de que esta não influi nas esferas jurídicas dos administrados. Em recente obra, Alfredo Gallego ANABITARTE, lamentando a pouca importância dada ao Direito Administrativo da Organização, afirma que "se o que justifica a presunção de validade das atuações administrativas é o fato de quem as leva a cabo estarem submetidos a regras de competência e de procedimento, não se pode ignorar que tais regras são de organização. O conhecimento da organização é, pois, prévio ao da atuação, ainda que ambos estejam indissoluvelmente vinculados" (Conceptos y Principios Fundamentales del Derecho de Organización, Ed. Marcial Pons, Madrid, 2001, p. 16). 
Estado. ${ }^{15}$ A tendência, no entanto, não parou nesta especialização, poderíamos dizer, ainda centralizada, da Administração Pública.

Expondo a evolução organizacional da Administração Pública, VITAL MOREI$\mathrm{RA}^{16}$ observa que "na concepção tradicional a administração pública apresentava um perfil unitário, baseado nos serviços departamentais hierarquizados, na direç̧ão governamental e na responsabilidade parlamentar do Governo pela actividade da administração. O modelo originário da administração pública do Estado constitucional era a "administração ministerial", isto é, a administração hierarquicamente organizada sob a égide de um Ministro responsável. (...) Hoje a "unidade da administração é uma fiç̧ão", sendo incontroversa a sua natureza "plurifórmica e pluricêntrica", (...) o que constitui "resultado natural da passagem do Estado burguês oitocentista, tipicamente monoclassista", voltado exclusivamente para a proteção dos interesses da burguesia então vitoriosa, para o Estado pluriclasse contemporâneo" (sufrágio universal, acesso democrático aos cargos da administração pública, desenvolvimento dos sindicatos, prestações estatais positivas etc.), "que necessariamente reflete na sua organização o incontornável e crescente pluralismo da organização social. (...) O pluralismo social e político provocou o pluralismo e a diferenciação organizatória da administração."

Sabino CASSESE observa que "a Administração italiana é - como, aliás, todas as Administrações dos países desenvolvidos - multiorganizativa, no sentido de que a amplitude e a variedade das funções públicas não apenas levaram à perda da unidade da organização do Estado, mas levaram-no também a adotar diversos modelos organizativos. As administrações públicas são, portanto, fragmentadas e diferenciadas. Por este motivo, é preferível dizer que a administração é multiorganizativa, antes que pluralística ou policêntrica. Estes termos muitas vezes não se referem a sujeitos, mas individuam apenas o primeiro (fragmentação), e não o segundo (diferenciação), dos dois caracteres acima indicados". ${ }^{17}$

Nos termos afirmados por Lorenzo Martín-Retortillo BAQUER, "cabe falar de um quadro policêntrico, dotado, ademais, de um elevado grau de polimorfismo: ampla pluralidade de organizações públicas com intensidades e matizes bastante complexos". ${ }^{18}$

15 Cf. MASSERA, Alberto, La Crisi del Sistema Ministeriale e lo Sviluppo degli Enti Pubblici e delle Autorità Amministrative Indipendenti, integrante da obra coletiva coordenada por Sabino Cassese e Claudio Franchini, La Amministrazione Pubblica Italiana - Um Profilo, Il Mulino, 1994, pp. 25-6.

16 Administração Autónoma e Associações Públicas, Coimbra, 1997, pp. 31-5.

17 CASSESE, Sabino, Le Basi del Diritto Amministrativo, Ed. Garzanti, Milão, $6^{*}$ ed., 2000, pp. 189 e 190. A diferença de nomenclatura em relação à adotada por Vital Moreira na citação acima ("plurifórmica" e "pluricêntrica") parece-nos pertinente, malgrado não entendermos que os termos "administração pluralista" ou "pluricêntrica" sejam desprovidos de importância. A preponderância que damos a estes termos no presente trabalho se deve ao seu foco centrar-se no fenômeno da criação de centros de poder autônomos no seio da Administração Pública, não nas diferentes formas organizativas que podem assumir, objeto que demandaria estudo específico.

18 BAQUER, Lorenzo Martín-Retortillo, Organismos Autónomos y Derechos Fundamentales, constante da obra coletiva Administración Instrumental - Libro Homenaje a Manuel Clavero Arevalo, Vol. I, Ed. Civitas, Madrid, 1994, p. 103. 
Naturalmente que nenhum modelo administrativo é inteiramente descentralizado/pluricêntrico em detrimento de uma até certo ponto necessária centralização. A adoção completa daquele levaria à desintegração da organização administrativa, e, a desta, à sua inviabilização prática. ${ }^{19}$

O que se verifica é a transformação dos modelos de administração pública, que passam a se situar no desenho organizativo e na gestão de recursos em função da natureza das tarefas, levando à fragmentação harmônica do aparato administrativo, à necessidade de novos instrumentos de integração e coordenação, e ao reconhecimento de novos graus do exercício autônomo da discricionariedade, com a emergência de mecanismos de controle mais finalísticos que hierárquicos.

As estruturas político-administrativas tradicionais, central-hierarquizadas, morosas e inspiradas por critérios preponderantemente políticos, revelaram-se, no contexto exposto, inadequadas para os desafios colocados ao Estado.

\section{II - Autonomia}

Sendo a autonomização de centros de poder administrativos o elemento essencial à Administração Pública pluricêntrica que vem se delineando em todo o mundo ocidental, inclusive no Direito Positivo brasileiro, mister se faz abordar o que deve ser entendido por autonomia.

Comparando-a com a soberania, Fezas VITAL ${ }^{20}$ afirma que esta é a "competência da competência, quer dizer, competência para marcar os limites da própria competência. E assim, se o poder político tiver competência para marcar os limites dentro dos quais exercerá o seu poder de dar ordens, dir-se-á soberano; mas se os limites dentro dos quais exerce o seu poder de dar ordens forem marcados, não por ele próprio, mas por outro poder, então dir-se-á não soberano", e, portanto, acrescentaríamos, autônomo.

José Afonso da SILVA denota que "a autonomia como poder próprio dentro de um círculo traçado por outro, pressupõe ao mesmo tempo uma zona de autodeterminação, que é o propriamente autônomo, e um conjunto de limitações e determinantes jurídicas extrínsecas, que é o heterônomo". ${ }^{21}$

Etimologicamente, autonomia significa a possibilidade de um ente jurídico estabelecer as normas da sua própria conduta. ${ }^{22}$

O conceito de autonomia só pode ser elaborado, em termos genéricos, como a margem limitada de liberdade de atuação conferida pelo ordenamento jurídico a

19 Para uma análise sistemática dos diversos graus de centralização e descentralização, ver Méndez, Sistemas Orgánicos, constante da obra coletiva Perspectivas del Derecho Público en la segunda Mitad del siglo XX, Madrid, 1969, pp. 951-2 e 956-7.

20 Direito Constitucional, Lisboa, p. 391.

21 Apud Luís Roberto BARROSO, Interpretação constitucional - Direito Constitucional Intertemporal. Autonomia desportiva: Conteúdo e Limites. Conceito de Normas Gerais, RDP, 97-96. 22 Do grego, auto, significa próprio, e, nomia, norma, regra. 
pessoas públicas ou privadas. Segundo o âmbito de liberdade concretamente definido pelo direito positivo, o sentido do termo pode sofrer grande variação. ${ }^{23} \mathrm{Um}$ conceito de autonomia mais rigoroso e definido só pode ser alcançado em função desta ou daquela autonomia específica, tal como juridicamente positivada.

Fora disso, como observa Silvio SPAVENTA, ${ }^{24}$ a autonomia "permanece indeterminada e indefinida. Ela pode exprimir um certo grau de independência e de autoridade reconhecida a uma pessoa jurídica; mas não há como se dizer qual seja este grau e esta medida de independência que lhe é atribuída."

No âmbito específico do Direito Administrativo, Ernst FORSTHOFF ${ }^{25}$ considera que os poucos efeitos práticos advindos da extensão da autonomia administrativa aos domínios da política social, econômica e cultural, podem ser explicados em razão da "autonomia administrativa ter se tornado tão genérica, a ponto de não podermos mais procurar uniformizar suas formas jurídicas."

Segundo VITAL MOREIRA, ${ }^{26}$ "é assaz polissêmica a noção de autonomia". Mais adiante, afirma o autor lusitano, em sua densa e profunda tese de doutorado, que "autonomia designa genericamente o espaço de liberdade de conduta de um ente face a outro. Concretamente no âmbito das pessoas colectivas públicas ela exprime a liberdade dos entes infra-estaduais face ao Estado, ou seja, a "relativa independência em relação ao poder central". Conforme os diversos campos em que essa liberdade de conduta pode manifestar-se, assim se pode falar em autonomia regulamentar, autonomia administrativa (stricto sensu), autonomia patrimonial e financeira etc. Neste sentido, a autonomia é uma questão de grau: pode ir de quase nada até à independência quase total. Nuns casos pode consistir senão na mera autonomia jurídica (existência de personalidade jurídica), sem nenhuma liberdade de acção; noutros casos pode ir até à mais ampla liberdade de decisão dentro da esfera de acção que lhe seja confiada ('administração independente')".

Especificamente em relação à autonomia normativa, entendemos que é difícil imaginar um ente autônomo que não a possua em alguma medida, por mais restrita que seja. A amplitude da autonomia normativa certamente pode variar, mas sempre existirá. Mesmo, por exemplo, a autonomia meramente administrativa, implica na faculdade de estabelecer normas específicas de administração interna.

T. Ramón FERNANDES ${ }^{27}$ assevera que a história prova que o conceito de autonomia alude a um certo poder de autonormação, e, por extensão, de autogoverno,

23 Uma percuciente classificação jurídica dos mais diversos conceitos de autonomia defendidos pela doutrina consta de ARNAUD, André-Jean (coord.), Dicionário Enciclopédico de Teoria e de Sociologia do Direito, tradução dirigida por Vicente de Paulo Barreto, Ed. Renovar, 1999, pp. 61/2. Para os mesmos fins, ver também Klaus STERN, in "Derecho del Estado de la República Federal Alemana", Centro de Estudios Constitucionales, 1987, trad. Javier Pérez Royo e Pedro Cruz Villalón, pp. 698 a 670 .

24 La Giustizia nell 'Amministrazione", Giulio Einaudi Editore, p. 153.

25 In "Traité de Droit Administratif Allemand", Bruylant, 1969, trad. Michel Fromont, p. 687.

26 In "Administração Autónoma e Associações Públicas", Coimbra Editora, 1997, pp. 69 e 70 (grifamos).

27 In "La Autonomía Universitaria: ámbito y limites", Civitas, 1982, p. 35. 
que existe e se reconhece para a melhor satisfação de um círculo específico e concreto de necessidades que a justificam em razão de sua própria singularidade e que, ao mesmo tempo, contribuem para precisar seus limites.

No mesmo sentido, Ignacio de OTTO ${ }^{28}$ afirma que, "em seu significado mais amplo, autonomia é o poder de indivíduos ou pessoas jurídicas para dar-se um ordenamento próprio nos limites de outro superior e mais amplo".

De toda sorte, as autonomias têm sempre que ser delimitadas caso a caso à luz dos termos em que são conferidas pelo Direito positivo. Dependendo da disciplina que receberem, poderão assumir realidades jurídicas das mais diversas. Deve-se destacar, no entanto, que, inclusive em razão do princípio do paralelismo das formas, apenas a fonte que confere a autonomia pode limitá-la.

\section{III - O princípio da descentralização administrativa}

A descentralização administrativa na Constituição brasileira decorre do que DIOGO DE FIGUEIREDO Moreira Neto ${ }^{29}$ qualifica como "os princípios técnicoadministrativos de maior relevo na reforma administrativa $:{ }^{30}$ o da autonomia e o da profissionalização".

Segundo o jurista, a Reforma Administrativa implicou "um passo racional na descentralização, com a finalidade de atender as diferentes necessidades de gestão da coisa pública segundo as suas características próprias e não em conformidade com um padrão rígido, formal e predeterminado".

Sem tal flexibilidade,${ }^{31}$ não seria possível à Administração, enrijecida em órgãos e funções hierárquica e burocraticamente estruturadas, atuar com eficácia e, muito menos, num mundo em mudança constante, com a eficiência e a economicidade preconizadas, respectivamente, pelo caput dos arts. 37 e 70 da Constituição Federal, que, ao fixar os fundamentos da República Federativa do Brasil, também assegura o "pluralismo do poder na sociedade (art. $1^{\circ}, \mathrm{V}$ ), enriquecido na consciência de sua importância tanto quanto à abertura e multiplicidade dos canais para a sua atuação" ${ }^{32}$

28 In "Derecho Constitucional - Sistemas de fuentes", Ariel, 1988, p. 245. Note-se que o autor expressamente cita a autonomia universitária como exemplo do conceito de autonomia por ele formulado.

29 In Apontamentos ..." cit., pp. 27 a 29.

30 O autor, naturalmente, está se referindo à Emenda Constitucional $n^{\circ} 19 / 98$.

31 "A idéia descentralizadora tem a sua força e utilidade nas novas exigências, na nova posição assumida pelo Estado como organismo social, na crescente necessidade advinda da complexização das relações, na assunção de novas funções, na necessidade de regular com presteza, igual e equanimemente, todas as manifestações da vida coletiva para cada parte do território. De fato, não seria possível a apenas uma organização centralizada dar conta destas necessidades, insuficiente e incapaz seria se não constituísse e reconhecesse subcentros os quais concorressem para a satisfação das necessidades públicas " (Carlo GIROLA, Teoria del Decentramento Amministrrativo, Fratelli Bocca Editore, Torino, 1929, p. 103)

32 Diogo de Figueiredo Moreira Neto, Curso de Direito Administrativo, Ed. Forense, $9^{\mathrm{a}}$ ed., 1990 , 
Em outra obra, o mesmo autor acresce que o princípio da eficiência (art. 37, caput, CF) “afasta qualquer burocratização de entidade ou de órgão público além do mínimo indispensável para o cumprimento das suas tarefas de rotina, ou seja, o desempenho das atividades-meio. De resto, todas as tarefas devem ser necessariamente orientadas pela atividade-fim, ou seja, pela finalidade". ${ }^{33}$

O publicista Massimo Severo GIANNINI, ${ }^{34}$ quando no exercício do cargo de Ministro da Função Pública da Itália, apresentou relatório ao Parlamento no qual levantou os principais problemas para que a Administração Pública adquirisse eficiência e economicidade. Ao tratar das técnicas de administração, manifestou especial preocupação com os chamados "custos ocultos", "constituídos pelo custo econômico adicional que representa a atividade administrativa exageradamente procedimentalista na qual participam mais órgãos que o necessário e com mais tramitações dilatadas por intervenções estéreis, que poderiam ser suprimidas sem prejuízo ao interesse público".

Ressalva que não se posiciona contrariamente a toda e qualquer formalidade ou procedimento, vez que, muitos deles são corolários do Estado de Direito, do devido processo legal e da necessidade de controle das contas públicas. Centra suas críticas, outrossim, sobre o emaranhado de procedimentalizações desnecessárias, de nível secundário, que servem muito mais ao jogo meramente interno do poder do que aos valores mais elevados do Estado de Direito.

Demonstrando, na prática, que a descentralização administrativa é ínsita aos princípios da eficiência e economicidade, MIGUEL REALE, ao dar parecer sobre proposta de descentralização, submetida à sua apreciação enquanto Membro do Conselho Administrativo do Estado de São Paulo, considerou que "serviços há, do mais alto e imediato interesse coletivo, que não podem continuar circunscritos à esfera do interesse particular, mas que, entretanto, pela sua própria natureza, exigem autonomia de ação, meios e processos de agir incompatíveis com os inevitáveis tropeços burocráticos. Um laboratório oficial de análises, por exemplo, em que cada pedido de material pelos analistas estiver sujeito a demorados e complexos trâmites

p. 99. Para muitos autores o princípio da descentralização também constitui emanação do princípio da subsidiariedade, pelo qual o Estado central só deve assumir as atribuições, as tarefas ou as incumbências que outras entidades existentes no seu âmbito e mais próximas das pessoas, dos seus problemas concretos, não possam assumir e exercer melhor e mais eficazmente (cf. Jorge MIRANDA, Manual de Direito Constitucional, Tomo III, Coimbra Editora, $4^{\mathrm{a}}$ ed., 1998). Como também ressalta Reinhold ZIPPELIUS, "a regulação de conflitos de interesses socialmente relevantes concretiza-se de maneira particularmente nítida em sociedades pluralistas, pela acção conjunta de todo um complexo de subsistemas" (Teoria Geral do Estado, trad. Karin Praefke-Aires Coutinho, Coordenação de J. J. Gomes CANOTILHO, Fundação Calouste Gulbenkian, 3ª ed., 1997, p. 27). Ainda ligando a idéia de descentralização administrativa à liberdade individual e à democracia pluralista, A. SALANDRA, Corso di Diritto Amministrativo, C. Manes, Roma, Atheneum, 1915, II, p. 39, passim.

33 Mutações do Direito Administrativo, Ed. Renovar, 2000, p. 24.

34 Apud PALAZZO, SESÍN, e Rolón LEMBEYE, La transformación del Estado, Depalma, 1992, pp. 12 e 13. 
de requisição, com audiência de remotas autoridades, será um laboratório falho, condenado a reduzir-se paulatinamente a uma simples denominação, ou a um mero arquivo de papéis sem vida". ${ }^{35}$

"Deste modo, adquiriu-se progressivamente a consciência de que, em relação à questão da descentralização, se trata de um problema de optimização, isto é, da tarefa de criar unidades organizatórias que realizam, caso a caso, un compromisso óptimo: entre as necessidades antagónicas de proximidade do assunto e do cidadão, auto-administração e auto-responsabilidade, por um lado, e regulação uniforme, coordenação e responsabilidade global, por outro". ${ }^{36}$

Não há, portanto, antagonismo entre a autonomia de entidades e órgãos materialmente descentralizados com a unidade da Administração, muito pelo contrário: a Administração Pública contemporânea, para cumprir as suas funções e atender aos valores e princípios constitucionais a ela impostos, deve atuar, ao mesmo tempo, coordenada e descentralizadamente. ${ }^{37}$

Vemo-nos, portanto, diante de um Direito Administrativo brasileiro mais complexo e plural, que abandona a idéia de que uma atividade administrativa só é racional na medida em que estiver previamente prevista, detalhadamente normatizada e sujeita a uma linha hierárquica; que a substituiu por técnicas de análise, gestão e responsabilidades estratégicas. ${ }^{38}$

\section{IV - Conceito material de descentralização administrativa}

Constatado o intrínseco liame existente entre a descentralização administrativa e a autonomia, mister se faz, para que eventuais dificuldades hermenêuticas possam ser mais facilmente contornadas, que teçamos um breve escorço sobre o conceito de descentralização, uma vez que o órgão ou entidade que materialmente possuir autonomia, será materialmente (não apenas formal ou nominalmente) descentralizado. ${ }^{39}$

35 As Autarquias Universitárias Paulistas, constante da coletânea Nos Quadrantes do Direito Positivo - Estudos e Pareceres, Gráfica-Editora Michalany Ltda., 1960, p. 140.

36 Reinhold ZIPPELIUS, in ob. cit., p. 129.

37 "A pluralidade dos centros de autonomia política, nos quais se expande o moderno ordenamento democrático, não significa desarticulação e atomização das suas estruturas" (Enrico Spagna MUSSO, L'Iniziativa nella Formazione della Legge Italiana, Napoli, 1958, p. 95).

38 Joan Prats i CATALÁ, Derecho y Management en las Administraciones Públicas - Notas sobre la crisis y Renovación de los respectivos paradigmas", pp. 9, 12 e 13 (fonte: www.crad.org.ve). Ver também DIOGO DE FIGUEIREDO Moreira Neto, nas obras Apontamentos sobre a Reforma Administrativa, Ed. Renovar, 1999, p. 04 e segs., e Sociedade, Estado e Administração Pública, Ed. Topbooks, 1995, pp. 142/4.

39 Com efeito. Maurice HAURIOU, tratando da matéria, conclui: “Il y a un autre aspect du sujet encore plis: intéressant: (...) la création des établissements publics (...) ne constitue pas, par elle même, une déccntralisation. Et il parait bien qu'elle en constitue une, si l'on réfléchit qu'elle s'accompagre nécessairement d'une répartition du pouvoir de décision" (in "Précis de Droit Administratif', Recueil Sirey, Paris, 1914, $8^{2}$ ed., p. 145). 
Classicamente, a descentralização é definida em contraposição à desconcentração.

A descentralização seria a criação de pessoas jurídicas pelo Estado, e a desconcentração a mera divisão de funções entre os diversos órgãos despersonalizados de uma mesma pessoa jurídica estatal, ou seja, seria a criação de órgãos periféricos dentro da própria Administração Direta.

Estes conceitos tradicionais de descentralização e desconcentração, na época em que nenhuma das duas acarretava significativa autonomia, não eram propriamente incorretos. Todavia, não mais correspondem ao modelo administrativo efetivamente descentralizado exigido, e já implantado, pelo Estado contemporâneo. Podemos, contudo, nos valer de ambos os conceitos, desde que lhes seja acrescentado um plus ontológico.

A mera criação de pessoa jurídica da Administração Indireta, sem que possua um grau de razoável autonomia para desenvolver suas atribuições, não tornará o seu desempenho mais ágil e eficiente. A desconcentração também é, por sua vez, mera forma de organização interna que não altera os vínculos hierárquicos tradicionais. Nenhuma delas, portanto, se tomadas nos seus conceitos tradicionais, constituirão necessariamente verdadeira descentralização.

Em todo o mundo, podemos constatar que a Administração Pública caminha para a descentralização em sentido material, sendo irrelevante a sua caracterização formal/tradicional, vista acima. O que importa é que a determinados centros de competência seja conferida considerável autonomia de atuação, independentemente deles serem constituídos ou não como pessoas jurídicas.

Propugnando pela relativização dos conceitos formais de órgão e de pessoa jurídica administrativa e, consequientemente, de desconcentração e descentralização em sentido meramente formal, Gaspar Ariño ORTIZ ${ }^{40}$ chega a observar que "o conceito estrito de pessoa jurídica, tal como elaborada pela pandectística do Direito privado resultava insuficiente para dar fundamento à razão da organização administrativa; o estrito dualismo órgão-pessoa só era capaz de explicar parcialmente a pluralidade de figuras subjetivas que podiam atuar em Direito Público de maneira juridicamente relevante. (...) Se pretenderá assim — digo — mediante a substituição da idéia unitária de "pessoa" (sujeito), pelas idéias-base de "capacidade", "imputação" e "legitimação", que são elementos singulares daquela (capacidade para ser titular de direitos, para figurar em juízo etc.)", alcançar um conceito material de ambos os institutos de molde a adequá-los às particularidades do Direito Público.

Há entidades descentralizadas, dotadas de personalidade jurídica, às quais a lei confere uma autonomia tão diminuta que, na prática, muito se assemelham aos órgãos internos subordinados hierarquicamente à Administração central. O contrário também se verifica: existem órgãos internos aos quais são atribuídas tão significativas atribuições autônomas, às vezes acompanhadas de garantias de permanência para

40 La Administración Institucional - Bases de su regimen juridico, Instituto de Estudios Administrativos, Madrid, 1972, pp. 32/3. 
seus titulares, que faz com que propiciem uma descentralização efetiva bem superior àquela das pessoas jurídicas apenas formalmente descentralizadas. ${ }^{41}$

Parte da doutrina afirma mesmo que os entes personalizados sem autonomia sequer podem ser considerados verdadeiras pessoas jurídicas. Por mais fortes razões, também não se poderia deles inferir qualquer descentralização. Ambas as categorias, centrais no mundo do Direito Administrativo, estariam falseadas.

Neste sentido é que Garrido FALLA, seguindo FERRARA, fala de "pessoas jurídicas fictícias", ${ }^{42}$ desprovidas de substrato real, ou seja, de um regime jurídico que realmente as trate como tal, que lhes confira um grau razoável de liberdade de agir.

Adotando o conceito material (efetivo, verdadeiro...) de descentralização, Alfredo Gallego ANABITARTE ${ }^{43}$ pronunciou-se no sentido de que "também se pode produzir a verdadeira descentralização em um sujeito ou centro de competências que não seja personalizado. (...) Não é essencial à descentralização que o sujeito descentralizado seja titular da competência que se lhe transfere (...). A usual definição de descentralização como "transferência da titularidade de competências entre pessoas jurídicas" não é mais que uma das hipóteses - a mais usual - de descentralização. Por outro lado, pode produzir-se esta transferência entre pessoas jurídicas como o caso das entidades da Administração Indireta, mas pode, todavia, não haver verdadeira descentralização em virtude da completa, e lógica tutela, a que se submete a atuação destas pessoas jurídicas."

41 Vincenzo Cerulli IRELLI, em termos análogos aos por nós adotados para conceituar os órgãos e entidades materialmente descentralizadas, define as autoridades administrativas independentes como "il fenomeno, emerso nell'esperienze più recente, delle c. $d$. autorità amministrative indipendenti, dotate o meno di personalità giuridica, costitute dalla legge per governare determinati settori di amministrazione in senso sostanziale, secondo moduli organizzativi e funzionali del tutto svincolati da qualsiasi relazione com l'organizzazzione ministeriale" (in "Corso di Diritto Amministrativo", G. Giappichelli Editore, Torino, 1997, p. 230). Diogo Freitas do AMARAL também chega ao mesmo resultado, só que, para manter a nomenclatura tradicional em relação aos órgãos autônomos despersonalizados, denomina os por nós chamados "órgãos descentralizados", de "órgãos com desconcentração absoluta" ou, similarmente a CERULLI, de "órgãos independentes": "Quanto aos 'graus de desconcentração', ela pode ser absoluta ou relativa: no primeiro caso, a desconcentração é tão intensa e é levada tão longe que os órgãos por ela atingidos se transformam em órgãos independentes; no segundo, a desconcentração é menos intensa e, embora atribuindo certas competências próprias a órgãos subalternos, mantém a subordinação destes aos poderes do superior. Neste último caso, a desconcentração e hierarquia coexistem, ao passo que naquele, pelo contrário, a desconcentração faz cessar a hierarquia" (Curso de Direito Administrativo, Livraria Almedina, 2* ed., 1998, pp. 660-1).

42 Apud Gaspar Ariño ORTIZ, in ob. cit., pp. 404-5.

43 In ob. cit., pp. 552-3 (grifamos). $O$ conceito de descentralização efetiva também encontra esteio na doutrina de Reinhold ZIPPELIUS: "Trata-se de desconcentração quando os membros de uma organização estão totalmente vinculados a instruções de instância central, e de descentralização quando estes membros gozam, no exercício das suas funções, de uma grande autonomia, p. ex., se unicamente se acham sujeitos a uma tutela de legalidade central ou, quando muito, a uma limitada tutela de mérito" (in ob. cit., p. 127, grifamos). 
É esta descentralização - material e efetiva - que leva ao pluricentrismo da Administração Pública contemporânea. Pouco importa, repita-se, que seja instrumentalizada em entidades dotadas de personalidade jurídica ou em órgãos internos despersonalizados.

Em todos estes casos haverá descentralização se forem outorgadas prerrogativas e garantias suficientes ao desempenho autônomo de funções destacadas do poder central. ${ }^{44} \mathrm{~A}$ nota fundamental é a não vinculação hierárquica.

\section{$V$ - Controles sobre os órgãos e entidades descentralizados}

A autonomia dos órgãos e entidades descentralizados é, como toda autonomia, limitada, não prescindindo de mecanismos de controle, que, todavia, não poderão ser hierárquicos, mas apenas de legalidade - serão de mérito apenas excepcionalmente - , gerenciais e finalísticos, implementados, notadamente, através da verificação do atendimento de metas e diretrizes preestabelecidas. ${ }^{45}$

Estes limites, além de não serem incompatíveis com a autonomia, integram o seu próprio conceito. Não seria de se imaginar, realmente, que um órgão ou ente descentralizado, por mais autônomo que fosse, ficasse alheio ao conjunto da Administração Pública. A autonomia não pode servir para isentá-los da obrigação de se inserirem nos planos e diretrizes públicas gerais. Se fossem colocados em compartimentos estanques, a descentralização revelar-se-ia antitética aos valores de eficiência e pluralismo que constituem o seu fundamento.

É apenas neste sentido, de inserção nos programas e diretrizes públicas gerais, que deve ser entendida a necessária subordinação dos órgãos e entidades descentralizados à Administração Pública central.

A lei ou o ato normativo que os instituir pode até dispor diversamente, estabelecendo uma hierarquia estrita, mas, neste caso, independentemente de ter havido ou não a criação de pessoa jurídica, não mais estaremos diante de descentralização propriamente dita, mas de mera desconcentração.

44 "La décentralisation implique que, pour assurer la marche de certains groupements de services, existent d'autres corps d'administration ayant une certaine liberté d'action. Le pouvoir central n'est pas eliminé, mais son rôle change. Il ne dirige plus. Il se borne à contrôler les autorités placées à la tête de ce corps d'administration propre" (Maurice HAURIOU, in "Précis de Droit Administratif", Dalloz, 1926, 92). Também vinculando o conceito de descentralização administrativa ao de autonomia, que seria um requisito daquela, A. Salandra, in "Corso di Diritto Amministrativo", C. Manes, Roma, Atheneum, 1915, II, p. 39, passim.

45 "Se pretende dar prioridade aos objetivos, aos índices de prestação e avaliação em relação ao orçamento, à comparação dos custos e às diversas unidades operativas, redimensionando o orçamento, concedendo aos dirigentes maior liberdade na gestão dos recursos e na prestação de contas do que tiver sido efetivamente realizado" (PALAZZO, SESÍN, y Rolón LEMBEYE, La transformación del Estado, Depalma, 1992, p. 94). 
Muitas vezes a subordinação é confundida com hierarquia. Todavia, nem toda subordinação de um órgão ou ente a outro constitui hierarquia, que, apesar de ser a mais forte, é apenas uma das espécies de subordinação.

Os mecanismos de controle hierárquico estão em franco processo de decadência ("sonno sotto accusa"), já " que se prestam a pouco, em relação ao custo econômico e burocrático, devendo deixar de fora todas as atividades executivas e técnicas. Estão, ao revés, demonstrando-se cada vez mais eficazes os controles do tipo budgeting, auditing, os controles de gestão, os controles internos de eficiência." ${ }^{46}$

As diferentes espécies de subordinação são, com a maestria que lhe é própria, assim enumeradas por Massimo Severo GIANNINI: ${ }^{47}$

(a) Hierarquia: Neste caso há uma relação de constante sujeição de um órgão ou ente a outro. Ela é a espécie mais antiga de subordinação e, por esta razão, às vezes é, equivocadamente, com ela confundida. Na hierarquia, temos uma total possibilidade de ingerência do órgão superior sobre o inferior, seja através da revogação ou anulação dos seus atos, na delegação ou avocação de competências, poder disciplinar etc. $O$ fenômeno se explica porque, na verdade "o órgão superior tem mesmo uma competência compreensiva da competência do órgão subordinado, fungível com a do órgão inferior". Nestes casos, o órgão hierarquicamente superior, não apenas possui poder de controle, como ainda de dar ordens e de substituição, pelo qual pode sempre substituir a ação do órgão ou da entidade, in casu, inferior;

(b) Direção: Nestes casos, um centro de competência não pode dar ordens ao outro, mas apenas fixar-lhe as diretrizes e controlar-lhe os resultados. $O$ controle exercido sobre o órgão subordinado não poderá consistir em poder de substituição, revogação, avocação ou em delegação obrigatória, e o poder de anulação, deve ser admitido excepcionalmente, apenas nos casos em que o ordenamento o admitir.

Fazendo a mesma distinção, mas com nomenclatura ligeiramente diversa, Vincenzo Cerulli IRELLI ${ }^{48}$ assinala que "o modelo originário de hierarquia (que denominamos de hierarquia em sentido estrito) caracteriza-se pelo fato de que entre os órgãos não existe uma verdadeira e própria separação de competências, mas as competências se confundem com as atribuições (própria da organização no seu complexo) no âmbito das quais todos os órgãos podem agir segundo critérios de distribuição de funções fixadas pelo vértice da organização e com valor fundamentalmente interno; assim, não é possível distinguir esferas próprias de competência dos órgãos a eles conferidas por lei que individuasse os poderes administrativos de sua própria titularidade. (...)

$\mathrm{Na}$ hierarquia em sentido amplo, os poderes sobre o órgão subordinado são bastante diversos daqueles próprios do primeiro modelo. Em vez do poder de dar ordens, temos o poder de direção: esse consiste no fato do superior hierárquico estabelecer critérios e objetivos da ação administrativa a ser desenvolvida pelo

46 Massimo Severo GIANNINI, in "Diritto Amministrativo", Volume I, Giuffrè Editore, Milão,

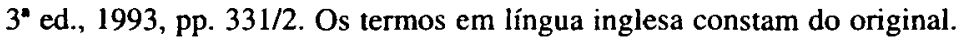

47 In ob. e vol. cit., pp. 311 a 333.

48 Corso di Diritto Amministrativo, $9^{a}$ ed., Giappichelli Editore, Torino, 1997, pp. 112/3. 
inferior hierárquico e titularizada por este último, critérios objetivos que o inferior deve ter em vista no desempenho das suas atividades, aos quais não deve, todavia, pura e simplesmente, obediência."

Se a subordinação dos órgãos descentralizados fosse da espécie hierárquica, não haveria descentralização, e, por outro lado, se não estivessem sujeitos a nenhuma subordinação (de direção), sequer integrariam a Administração Pública descentralizada.

Naturalmente que os controles de direção podem variar bastante, tanto de natureza como em intensidade. Mas, verificados os traços básicos acima analisados, estaremos, sem dúvida, diante de órgãos ou entes descentralizados.

\section{$V I$ - O caso das agências reguladoras}

Vimos nos Tópicos anteriores a tendência de descentralização material da Administração Pública contemporânea, com a criação de órgãos e entidades estatais dotadas de significativa autonomia frente ao Poder político-estatal central. ${ }^{49}$

Com efeito, "o desenvolvimento de uma administração independente, dispondo de poderes decisórios regulamentares e individuais, necessita de um espaço administrativo suficientemente 'aberto'. Não há qualquer possibilidade (teórica ou prática) destas instituições se desenvolverem em espaços administrativos 'fechados', organizados e controlados de maneira rígida". 50

É neste contexto que, em todo o mundo ocidental, se avulta a importância das agências reguladoras independentes, principalmente naqueles setores sensíveis à articulação do Estado com a sociedade, entre os quais destacam-se os que foram objeto de desestatização. ${ }^{51}$

O tantas vezes repisado caráter de "independência" das agências reguladoras retrata na verdade uma autonomia reforçada, uma maior autonomia em relação à de que normalmente são dotadas as demais entidades da Administração Indireta, que

49 "O aparato burocrático das administrações estatais constitui um complexo de corpos ligados pelo fato de pertencerem à mesma organização política unitária (e não, ao revés, um corpo maciço em si unitário); que cada um dos corpos possui uma relevância política em decorrência da especialização inerente à meritocracia" (Massimo Severo GIANNINI, apud CASSESE, Sabino, Lo "Stato Pluriclasse" in Massimo Severo Giannini, constante da obra coletiva L'Unità del Diritto Massimo Severo Giannini e la Teoria Giuridica, Società Editrice Il Mulino, Bologna, 1994, p. 28). 50 MODERNE, Frank, Les Modèles Étrangers, constante da obra coletiva Les Autorités Administratives Indépendantes, coordenada por Claude-Albert Colliard e Gerard Timsit, PUF, Paris, 1988, pp. 190.

51 QUERMONNE, Jean-Louis, L'Appareil Administratif de l'État, Éditions du Seuil, Paris, 1991, p. 256. Pierre DELVOLVÉ afirma que a criação destas entidades "se justifica pela vontade de instituir, em setores delicados, concernentes particularmente às liberdades públicas e à regulação de atividades econômicas, órgãos dotados simultaneamente de imparcialidade, competência técnica e poder de influenciar os atores sociais envolvidos" (Droit Public de l'Économie, Dalloz, Paris, 1998, p. 264). 
em sua maioria não são materialmente descentralizadas (cf. Tópicos IV e V). Neste sentido, as principais notas da autonomia/independência das agências reguladoras são a impossibilidade de exoneração ad nutum dos seus dirigentes ${ }^{52}$ a organização colegiada; a formação técnica; competências regulatórias e a impossibilidade de recursos hierárquicos impróprios, sendo que apenas a conjunção destes elementos resultará na conceituação de uma entidade como agência reguladora independente. ${ }^{53}$

Não podemos, porém, ter o simplismo de achar que as agências reguladoras independentes constituem a totalidade do fenômeno do pluricentrismo administrativo. Se, por um lado, de fato representam uma grande potencialização do pluricentrismo da Administração Pública, por outro, esta tendência não se originou com elas, possuindo raízes bem mais profundas; ${ }^{54}$ e mais, o próprio atual movimento de

52 As restrições ao poder de livre nomeação e exoneração pelo Chefe do Poder Executivo, principal nota características da sua "independência", foram consideradas constitucionais pelo Supremo Tribunal Federal no julgamento da Medida Cautelar pedida na ADIN n ${ }^{\circ}$ 1949-0. A primeira em virtude do art. 52, III, 'f', Constituição Federal, admitir a prévia aprovação do Senado Federal da escolha de "titulares de outros cargos que a lei determinar". Quanto à constitucionalidade da vedação da exoneração ad nutum dos dirigentes das agências reguladoras independentes, o Supremo entendeu que não viola as competências do Chefe do Poder Executivo, admitindo a exoneração apenas por justa causa e mediante prévio procedimento administrativo, assegurado o contraditório e a ampla defesa, ou se advier a mudança da lei criadora da agência independente (fonte: "http://www.stf.gov.br").

53 Elisenda MALARET observa que, "apesar da atribuição de personalidade jurídica implicar sempre no reconhecimento de um certo grau de autonomia, na hipótese agora considerada a autonomia não é tanto a consequiência, mas uma das condições que garantem a efetividade do cumprimento da tarefa atribuída. Evidentemente, sempre que a personificação seja acompanhada dos correspondentes recursos pessoais e financeirose que o reconhecimento de poderes e a respectiva atribuição de competências configure um âmbito de livre configuração sem a adoção de mecanismos administrativos de controle ou de tutela" (MALARET, Elisenda, Comisión Nacional del Mercado de Valores (Una aproximación a su configuración institucional, Revista Española de Derecho Administrativo - REDA - versão CD-ROM).

54 "A mera separaçāo de um órgão administrativo da linha hierárquica ou a garantia de inamovibilidade dos seus membros durante um período determinado para reforçar a sua posição na organização e a objetividade de suas decisões são técnicas já há muito conhecidas e que não são suficientes, por si sós, para configurar uma autoridade administrativa independente no sentido aqui tratado, assim como não o é, tampouco, obviamente, a simples personificação formal de uma entidade administrativa qualquer" (RODRÍGUEZ, Tomás Ramón Fernandez, Reflexiones sobre las Llamadas Autoridades Administrativas Independientes, constante da obra coletiva Administración Instrumental - Libro Homenaje a Manuel Clavero Arevalo, Vol. I, Ed. Civitas, Madrid, 1994, p. 439). Na mesma senda, ver QUERMONNE, Jean-Louis, L'Appareil Administratif de l'État, Éditions du Seuil, Paris, 1991, p. 258. Para uma relevante apreciação da conexão existente entre as idéias que deram origem às autoridades de autonomia reforçada analisadas $e$ antigas doutrinas de juristas europeus, mormente as de HAURIOU e DUGUIT, remetemos o leitor a RAMÓN, Fernando LÓPEZ, El Consejo de Seguridad Nuclear: Un Ejemplo de Administración Independiente, pp. 577/8 e Parada VÁSQUES, José Ramón, Las Administraciones Independientes, pp. 665/6, ambos constantes da obra coletiva Administración Instrumental - Libro Homenaje a Manuel Clavero Arevalo, Vol. I, Ed. Civitas, Madrid, 1994. Realizando uma análise das autoridades administrativas independentes como decorrência da doutrina dos poderes neutrais do Estado que remonta a Benjamin 
complexização e multiorganização administrativa não se reduz ao modelo das agências reguladoras independentes,${ }^{55}$ havendo um sem-número de entidades que também se subsumem aos mesmos paradigmas de autonomização/descentralização material dos centros decisórios públicos (universidades, ${ }^{56}$ conselhos profissionais, entes independentes desprovidos de competências regulatórias, órgãos constitucionais independentes, ${ }^{57}$ etc.). ${ }^{58}$

Segundo DIOGO DE FIGUEIREDO MOREIRA NETO, as “agências governamentais autônomas, entendidas como entes fracionários do aparelho administrativo do Estado, não são tema novo no Direito Administrativo. (...) A novidade está no ressurgimento da importância dessas entidades, rebatizadas, resumidamente, de agências reguladoras, para desempenharem autarquicamente essas funções na disciplina de certos serviços, cuja execução vem sendo transferida de empresas estatais para empresas privadas". 59

Também FRANCESCO PAOLO CASAVOLA afirma "que um Estado que esteja dentro, não à frente, dos processos sociais deve encontrar instrumentos que sejam independentes dos poderes originários e constitutivos da estatalidade - o Governo e o Parlamento. E deve encontrar pessoas eticamente independentes que não tenham ideologia ou interesse como parte nos processos sociais". ${ }^{60}$

A maior parte das agências reguladoras independentes criadas no Brasil guarda pertinência com a retração da intervenção estatal em vastos setores da economia, que teve como reverso a consciência de que o Estado não poderia deixar apenas ao bom senso empresarial a gestão de atividades de indubitável interesse público, que

CONSTANT e Carl Schmitt, SALA ARQUER, José Manuel, El Estado neutral. Contribución al estudio de las administraciones independientes, Revista Española de Derecho Administrativo REDA, vol. 42, 1984.

55 Também em França Jean-Louis QUERMONNE adverte que "a dispersão dos centros de decisão, que leva à multiplicação das autoridades administrativas independentes, se inscreve em um vasto movimento de questionamento do monolitismo da Administração" (QUERMONNE, Jean-Louis, L'Appareil Administratif de l'État, Éditions du Seuil, Paris, 1991, p. 266, grifamos).

56 Alexandre Santos de ARAGÃO, A Autonomia Universitária no Estado Contemporâneo e no Direito Positivo Brasileiro, Ed. Lumen Juris, 2001.

57 Ver DIOGO DE FIGUEIREDO Moreira Neto, Algumas Notas sobre Órgãos Constitucionalmente Autônomos - Um estudo de caso sobre os tribunais de Contas no Brasil, RDA, 223/01-28. 58 Já em 1968 Celso Antônio BANDEIRA DE MELLO lecionava: "Nas autarquias corporativas profissionais (como a Ordem dos Advogados, o Conselho Nacional de Medicina, por exemplo) seus administradores são escolhidos pelos próprios corporados, sem interferência da Administração Central, conforme dispõem suas respectivas leis. Em outras entidades autárquicas o poder de nomeação do Chefe do executivo é atenuado. Fica adstrito à escolha de um dentre vários nomes que the são apresentados em lista organizada internamente na entidade autárquica. Sirva de exemplo a nomeação de reitores de Universidades" (BANDEIRA DE MELLO, Celso Antônio, Natureza e Regime Jurídico das Autarquias, Ed. RT, São Paulo, 1968, p. 454).

59 Mutaçōes do Direito Administrativo, Ed. Renovar, Rio de Janeiro, 2000, p. 145-6.

60 CASAVOLA, Francesco Paolo, Quale 'statuto' per le Autorità Indipendenti, constante da obra coletiva Regolazione e Garanzia del Pluralismo - Le Autorità Amministrative Indipendenti, Ed. Giuffrè, Milano, 1997, pp. 25-6, grifamos. 
deveriam, portanto, ficar sob o seu poder regulatório. Procurou-se, todavia, fazer com que a regulação de tais atividades não ficasse sujeita à variação dos humores político-partidários, dotando-se as entidades dela incumbidas de uma especial autonomia em relação ao Poder Executivo central, autonomia esta cuja principal nota é a nomeação de técnicos por mandato determinado, durante o qual é vedada a exoneração ad nutum.

Todavia, em um segundo momento o Legislador estendeu este modelo de regulação a uma série de atividades econômicas stricto sensu, que sempre estiveram sob a égide da iniciativa privada, fazendo com que passassem a ser reguladas por entidades dotadas, nos mesmos moldes, de autonomia frente ao poder hierárquico central. $^{61}$

Adverte-se que o modelo não representa, em sua substância, um apequenamento do Legislador ou da política pública por ele traçada para o setor a ser regulado pela agência independente. Ao contrário, deve levar a uma certa perenização das finalidades públicas traçadas pela lei do setor, que não mais ficam - ou não deveriam ficar - variando de acordo com o fugaz momento político.

Para tanto, tais entidades foram dotadas de amplos poderes, notadamente de natureza normativa, ${ }^{62}$ vez que, de outra forma, não poderiam desempenhar satisfatoriamente (agilidade, informalidade, constante adaptação à realidade cambiante etc.) suas atribuições, o que exige ainda um corpo de titulares revestidos das prerrogativas necessárias à manutenção da sua impermeabilidade face aos interesses políticos transitórios e, não se olvide, aos interesses econômicos regulados.

\section{VII - Conclusões}

A insurgência de espaços administrativos efetivamente autônomos frente ao Poder Executivo central, do que as agências reguladoras independentes constituem o exemplo mais relevante em nosso Direito Positivo, é uma exigência da eficácia da regulação estatal em uma sociedade que, tal como o Estado, se torna cada vez mais diferenciada e complexa.

Todavia, a adoção de um modelo multiorganizativo e pluricêntrico de Administração Pública traz riscos à legitimidade democrática da sua atuação. Em outras palavras, uma das suas maiores vantagens - a distância dos critérios político-par-

61 De fato, após uma primeira geração de agências reguladoras de serviços públicos desestatizados, surgiram as agências reguladoras de atividades econômicas, principalmente na área da saúde - $\mathbf{A}$ Agência Nacional de Vigilância Sanitária - ANVISA (Lei n 9.782/99) e a Agência Nacional de Saúde Complementar - ANSP (Lei n 9.961/2000). Também poderíamos aludir à Agência Nacional do Petróleo nos aspectos de sua regulação que não incidem sobre a atividade monopolizada pela União, mas sobre meras atividades privadas sujeitas à autorização administrativa, a exemplo da distribuição de combustíveis, que nunca foi estatizada.

62 A este respeito, Alexandre Santos de ARAGÃO, O Poder Normativo das Agências Reguladoras, Revista Forense, 354/03-26, e HUGHES, Some Aspects of Development of American Law, 1916, 39, New York State Bar Association Reports, 266/269. 
tidários de decisão, assegurada sobretudo pela impossibilidade do Chefe do Poder Executivo (eleito) exonerar livremente os seus dirigentes (nomeados) - é também um dos seus maiores riscos.

Para evitar o desvio democrático destas instituições devemos ter sempre clara a sua vinculação às pautas estabelecidas pelo Legislador para as políticas públicas cuja implementação lhes é atribuída, assim como a necessária coordenação que devem possuir com o restante da Administração Pública, com o Poder Executivo central e com a rede composta do conjunto das demais instituições independentes. ${ }^{63}$ A nomenclatura "independente" é, assim, apenas um meio de denotar a sua autonomia reforçada, que, todavia, é, como toda autonomia, por definição limitada.

Assim, podemos adotar as conclusões a que em relação ao tema chegou JeanLouis QUERMONNE, já que, "longe de propugnar um retorno ao monolitismo cuja nostalgia sobrevive nos espíritos jacobinos - a prática das autoridades administrativas independentes deve favorecer uma evolução que promova um policentrismo equilibrado. Não se trata, certamente, de uma receita mágica. E não podemos confundi-la com a evolução simétrica, que consistiria em menosprezar as administrações centrais - a que seriam reservadas as funções de concepção, de coordenação e de controle - em benefício do agenciamento às estruturas mais ágeis e adaptadas - tais como aquelas que se desenvolvem no domínio das telecomunicações - às quais seriam confiadas as responsabilidades de gestão." ${ }^{64}$

Este foi o modelo adotado no Direito brasileiro - e já chancelado pelo Supremo Tribunal Federal - em relação às agências reguladoras e outros órgãos e entidades similares, dotados de ampla autonomia decisória, autonomia esta que, contudo, é instrumental à realização dos objetivos fixados na lei e nas políticas públicas estabelecidas pela Administração central.

63 É comum que esta coordenação seja levada a cabo por órgãos colegiados, dos quais participam representantes de órgãos de vários setores. Estes órgãos colegiados estabelecem as políticas gerais cuja realização deve ser perseguida pelas instituições reguladoras. Veja-se, por exemplo, que a regulação empreendida pela Agência Nacional do Petróleo - ANP deve implementar as políticas gerais traçadas pelo Conselho Nacional de Política Energética - CNPE (art. $8^{\circ}$, I, Lei ${ }^{\circ}$ 9.478/97). Outro mecanismo encontradiço é a celebração de convênios entre diversos entes reguladores para tratar com harmonia os casos atinentes a mais de uma esfera regulatória. Neste escopo, a maior parte das agências reguladoras celebrou convênio com o Conselho Administrativo de Defesa da Economia - CADE.

64 QUERMONNE, Jean-Louis, L'Appareil Administratif de l'État, Éditions du Seuil, Paris, 1991, pp. 268/9. 